\title{
DIFERENCIAÇÃO GENÉTICA ENTRE PROCEDÊNCIAS DE AÇAIZEIRO POR MARCADORES RAPD E SSR ${ }^{1}$
}

\author{
MARIA DO SOCORRO PADILHA DE OLIVEIRA² \& KAESEL JACKSON DAMASCENO E SILVA
}

RESUMO - Diferenciação genética refere-se à distribuição da variabilidade entre e dentro de populações, procedências ou outros tipos de agrupamentos. Seu conhecimento é importante para estabelecer estratégias de coleta, conservação e manejo de germoplasma de qualquer espécie. Neste trabalho, avaliou-se a diferenciação genética entre procedências de açaizeiro que compõem a coleção da Embrapa Amazônia Oriental, por meio de marcadores RAPD e SSR. Para tanto, foram utilizados DNAs de 107 acessos, representantes de 17 regiões geográficas diferentes e utilizados em PCR com 28 primers RAPD e sete primers SSR. Os dados foram submetidos à análise de variância molecular (AMOVA) com estrutura hierárquica desbalanceada. Altos níveis de diferenciação genética foram registrados entre procedências, com 0,301 para o marcador dominante e 0,242 para o co-dominante. Para os dois marcadores, a AMOVA apresentou grande variabilidade dentro das procedências (acima de 69\%). O pequeno tamanho amostral das procedências do Maranhão pode ter contribuído para a diferenciação significativa entre procedências. Os dados obtidos por esses marcadores foram concordantes quanto à distribuição da variação genética entre e dentro de procedências dessa palmeira.

Termos para indexação: Amazônia, germoplasma, Euterpe, palmeira,variação genética.

\section{GENETIC DIFFERENTIATION IN PROVENANCES OF AÇAÍ TREE BY RAPD AND SSR MARKERS}

\begin{abstract}
Genetic differentiation refers to the distribution of the variability among and within populations, provenances or other grouping types. This knowledge is important to establish collection strategies, conservation and germplasm management of any species. In this work, the genetic differentiation was evaluated among provenances of açaí tree from Embrapa Eastern Amazon germplasm collection using RAPD and SSR markers. DNAs of 107 accessions, representing 17 different geographic regions were used in PCR reactions with 28 RAPD primers and seven SSR primers. The obtained data was submitted to analyses of molecular variance (AMOVA) with unbalanced hierarchical structure. High levels of genetic differentiation were registered among provenances, with 0.301 for the dominant marker (RAPD) and 0.242 for the codominante (SSR). For the two markers, AMOVA showed a great variability within the provenances (above 69\%). The small sampling size of Maranhão provenances might have contributed to the significant differentiation among these provenances. The data obtained by these markers were in agreement with in what concerns the distribution of the genetic variation among and within the provenances of this palm tree.
\end{abstract}

Index terms: Amazon, Germplasm, Euterpe, Palm, Genetic variation.

\section{INTRODUÇÃO}

A diferenciação genética refere-se à distribuição da variabilidade entre e dentro de populações e subpopulações naturais, procedências ou outros tipos de agrupamentos, onde os alelos e os genótipos ocorrem de maneira heterogênea no espaço e no tempo, isto é, resultado da ação de forças evolutivas que atuam dentro do contexto de cada espécie (Hamrick, 1982). Esse conhecimento é um importante passo para se estabelecerem estratégias de coleta, conservação e manejo de germoplasmas mais eficientes, uma vez que as coletas devem contemplar a maior diversidade genética possível da espécie do maior número possível de locais. Como o açaizeiro (Euterpe oleracea Mart.) é uma espécie perene nativa da amazônica, de forte expansão no mercado de polpa, em virtude do alto valor nutricional de seus frutos (Oliveira et al., 2007), estudos dessa natureza tornam-se imprescindíveis,pois germoplasmas dessa fruteira conservados na forma ex situ, servem de base para programas de melhoramento genético.
A avaliação da diferenciação genética inter e intra populações, procedências, tipos e variedades conservadas em bancos ou coleções de germoplasma requer estudos específicos para que essas populações sejam bem manejadas e domesticadas (Cardoso et al., 2000). Diversos fatores podem afetar a distribuição da variabilidade genética como: o tamanho da população, o modo de reprodução (sexual e assexual), o sistema de reprodução (autofecundação, cruzamento e misto), o fluxo gênico (dispersão de sementes e pólen) e os tipos de ambientes em que a espécie ocorre (Hamrick, 1982). Outros fatores também podem afetar a porcentagem de variação genética, como a fragmentação florestal (desflorestamento e exploração) e a ação antrópica (Rotman \& Boyle, 2000). Os principais efeitos desses fatores envolvem a redução da diversidade genética, a ocorrência de deriva genética e o aumento na taxa de endogamia, fazendo com que ocorra maior diferenciação genética entre subpopulações, pois o fluxo gênico fica prejudicado, principalmente se seus polinizadores forem animais.

Inferências seguras sobre a estruturação genética podem

1(Trabalho 140-07). Recebido em: 05-06-2007. Aceito para publicação em: 01-02-2008.

2Embrapa Amazônia Oriental. Caixa Postal 48. CEP 66095-100 Belém, PA. E-mail: spadilha@cpatu.embrapa.br.

${ }^{3}$ Embrapa Meio Norte. Caixa Postal 001. CEP 64006-220 Teresina, PI. E-mail: kaesel@cpmn.embrapa.br.

Rev. Bras. Frutic., Jaboticabal - SP, v. 30, n. 2, p. 438-443, Junho 2008 
ser obtidas por meio de marcadores moleculares, mas envolvem diferentes metodologias, dependendo do tipo de marcador, se dominante (Zucchi et al., 2003) ou co-dominante (Zucchi et al., 2005). Para marcadores co-dominantes, há várias estatísticas: $F$ de Wright, que permite determinar a distribuição da variabilidade genética entre as populações $\left(\mathrm{F}_{S T}\right)$ e os níveis médios de endogamia populacional $\left(\mathrm{F}_{I S}\right)$ e total $\left(\mathrm{F}_{I T}\right)$; coeficientes de coancestralidade de Cockerham $(\theta)$, que possibilitam a avaliação da divergência em diferentes níveis de hierarquia e estimativas de endogamia; análise da diversidade gênica em populações subdivididas, que compara os níveis de heterozigosidade entre e dentro das populações; e pela estatística $\phi_{S T}$, que estima componentes de variâncias análogos às estatísticas $\mathrm{F}$ de Wright, por meio da análise de variância molecular (AMOVA). Tais abordagens possuem bases genéticas similares, além de serem complementares quanto ao significado biológico das estimativas. No caso de marcadores dominantes, a quantificação da variabilidade só foi possível a partir da introdução da estatística $\phi_{\text {st }}$, sendo facilmente aplicável em diferentes situações por constituir uma estrutura coerente e flexível para a análise de dados moleculares. Para Mohammadi \& Prasanna (2003), a AMOVA pode ser empregada em qualquer grupo de indivíduos e classe de marcadores.

A AMOVA vem sendo aplicada para determinar níveis de diferenciação genética em germoplasma de palmeiras (populações, tipos, ecotipos, etc.) conservados em bancos e/ ou coleções de germoplasma, com base em diferentes classes de marcadores moleculares, como no palmiteiro (Cardoso et al., 2000), no coqueiro (Perera et al., 2001) e no dendezeiro (Hayati et al., 2004). Entretanto, não há registros para agrupamentos de palmeiras pertencentes à espécie Euterpe oleracea e conservados em coleções de germoplasma.

Este trabalho teve por objetivo avaliar a diferenciação genética entre procedências de açaizeiro conservadas na forma ex situ em coleção de germoplasma, por meio de marcadores RAPD e SSR, utilizando o procedimento AMOVA.

\section{MATERIAL E MÉTODOS}

\section{- Extração de DNA}

Para a extração de DNA, foram retirados folíolos da folha mais jovem de 484 plantas, de 107 acessos de açaizeiro conservados na Coleção de Germoplasma da Embrapa Amazônia Oriental. A maioria foi oriunda de coletas realizadas em 16 locais de ocorrência natural da espécie e uma recebida de intercâmbio (Tabela 1). A extração do DNA genômico total foi realizada no Laboratório de Genética Molecular, do Departamento de Biologia da Universidade Federal de Lavras-MG e seguiu procedimento semelhante ao de Nienhuis et al. (1995). Com os DNAs das plantas representantes de cada acesso, obtiveram-se 107 misturas eqüitativas (bulks), de forma a restaurar o DNA de cada planta no local da coleta, as quais foram empregadas nas reações. foram aplicados em gel de agarose ultrapura (Invitrogen), na concentração de $1 \%$, e separados por eletroforese, em cuba horizontal. No caso das reações SSR, estas foram preparadas no volume de $17 \mu \mathrm{L}$, utilizando-se de sete locos (Tabela 2), que apresentaram transferibilidade de Euterpe edulis para E. oleracea (Oliveira, 2005). Os fragmentos foram separados em gel de agarose ultrapura 1.000 (Invitrogen), na concentração de 2,5\%, e separados por eletroforese, em cuba horizontal, considerado por Senior et al. (1998) como eficiente na detecção de polimorfismo por microssatélites. Todos os géis foram tratados com brometo de etídio, visualizados em transiluminador de luz ultravioleta e as imagens capturadas em câmera digital e arquivadas para avaliação das bandas (Figura 1). Detalhes sobre essas reações encontramse mencionados em Oliveira (2005).

\section{- Análise dos dados}

Os dados obtidos pelos marcadores RAPD foram identificados por meio de bandas polimórficas, cuja presença foi representada por " 1 ", e a ausência por " 0 ", sendo organizados em uma matriz binária, enquanto as bandas geradas pelos marcadores SSR foram codificadas, inicialmente, por 1 (presença) e 0 (ausência), e depois lidas como dados genotípicos.

As estimativas da diferenciação genética foram obtidas pelo procedimento da análise de variância molecular (AMOVA), com base em 263 bandas polimórficas e em 42 alelos. As análises foram efetuadas para 17 procedências e 107 acessos e processadas no software Arlequin 2.000 (Schneider et al., 2000), considerando os dados dos marcadores RAPD como dominantes (RFLP), e os gerados pelos marcadores SSR, como co-dominantes (MICROSAT). Utilizou-se uma estrutura hierárquica desbalanceada, uma vez que o número de acessos por procedência foi variável, em que cada procedência foi considerada uma população. Nesse modelo, a variância genética total $\left(\sigma_{T}^{2}\right)$ corresponde ao somatório da variância entre procedências $\left(\sigma_{p}^{2}\right)$ e a variância entre acessos dentro de procedências $\left(\sigma_{a}^{2}\right)$, onde os componentes de variância foram testados a partir do coeficiente $\phi_{S T}$ (Excoffier et al., 1992).

$$
\phi_{S T}=\frac{\sigma_{\mathrm{p}}^{2}}{\sigma_{T}^{2}}
$$

Em que:

$\phi_{S T}$ : representa o valor dos acessos tomados ao acaso dentro das procedências em relação aos acessos tomados ao acaso em toda a amostra;

$\sigma_{p}^{2}$ : componente de variância devido às diferenças entre procedências;

$\sigma_{a}^{2}$ : componente de variância devido às diferenças entre acessos dentro de procedências.

O teste de significância para as estimativas foi realizado com base em bootstrap, considerando 10.100 reamostragens, conforme estabelecido no software Arlequin 2.000.

\section{- Reações PCR}

As reações RAPD foram efetuadas para o volume de $16 \mu \mathrm{L}$, empregando-se 28 primers (Oliveira, 2005). Os produtos da reação 


\section{RESULTADOS E DISCUSSÃO}

Para os marcadores RAPD, observa-se que a variância entre procedências foi alta e significativa $\left(\phi_{S T}=0,301, \mathrm{P} \leq 0,0001\right)$, correspondendo a $30,12 \%$ da variação genética total, o que indica níveis relativamente altos de diferenciação genética entre elas (Tabela 3). Mesmo assim, verifica-se que grande parte da variação ficou retida dentro dos locais de coletas, evidenciando ampla variabilidade entre os acessos de cada procedência $(75,85 \%)$. A alta porcentagem de variação entre procedências pode ter sido influenciada pela ação antrópica, uma vez que a maioria dos acessos foi coletada em pomar caseiro ou propriedade rural. Resultados semelhantes foram registrados entre populações naturais do palmiteiro (Cardoso et al., 2000) com o uso de AFLP e raças de pupunheira (Rodrigues et al., 2004) por RAPD, ambos marcadores dominantes. Mas, em outras palmeiras, os percentuais de variação genética foram bastante variáveis (Adin et al., 2004; Moretzohn et al., 2002; Perera et al., 2001). De acordo com Bawa (1992), plantas arbóreas tropicais de fecundação cruzada podem apresentar variações na porcentagem de diferenciação genética entre populações, dependendo da espécie.

A partição da variação entre populações naturais de outras espécies tropicais, perenes e alógamas, analisadas também por marcadores RAPD, tem apresentado porcentagem próxima ou mais elevada que a encontrada neste estudo (Araújo, 2001; Carvalho et al., 2003; Fontaine et al., 2004; Wadt \& Kageyama, 2004; Zucchi et al., 2003). Para Zucchi et al. (2003), o alto nível de diferenciação genética entre populações de cagaiteira $\left(\phi_{S T}=0,2703\right)$ é decorrente de efeitos da deriva genética, ocasionados pela ação antrópica e pela predominância de fluxo gênico a pequenas distâncias. Acredita-se que as procedências de açaizeiro aqui estudadas também estejam sofrendo a ação desses mesmos efeitos, ou que o sistema de dispersão de pólen e sementes dessa espécie não seja tão eficiente, como constatado por Moura et al. (2005) ao avaliar a distribuição da variação entre locais de coleta de jaborandi. A alta diferenciação entre procedências pode ter sido influenciada, também, pelo pequeno tamanho amostral presente na metade dos locais avaliados ( $\mathrm{N}=2$ acessos), especialmente nas procedências maranhenses.

Nos resultados com os marcadores SSR, percebe-se que a AMOVA também revelou diferença significativa entre procedências $(0,242, \mathrm{P} \leq 0,0001)$, retendo $24,15 \%$ da variação total e, por conseguinte, alto nível de diferenciação genética (Tabela 3). Entretanto, a maior parte da proporção ainda ficou retida dentro de procedências, respondendo por $69,88 \%$ da variação. Isso indica, mais uma vez, a existência de maior variabilidade dentro de procedências do que entre as mesmas, fato comum para espécies alógamas, como o açaizeiro. Maior porcentagem dentro de procedências poderia ser registrada se a genotipagem fosse realizada em gel vertical de poliacrilamida. Níveis de diferenciação genética semelhantes foram obtidos com o uso de SSR e de outros marcadores co-dominantes em germoplasma de dendezeiro (Hayati et al., 2004) e em populações naturais de palmiteiro submetidas à ação antrópica (Conte, 2004). Neste último trabalho, as altas taxas de diferenciação foram atribuídas a cruzamentos não-aleatórios entre indivíduos aparentados (5\%) e biparentais $(10 \%)$, apesar de essa espécie reproduzir-se por alogamia. Souza (2002) registrou taxa de cruzamento de 12,9\% entre indivíduos aparentados em uma população natural de açaizeiro de Breves-PA, por meio de marcadores SSR. Tais prerrogativas podem ser inferidas às procedências de açaizeiro aqui avaliadas, em função da ocorrência de fluxo gênico via pólen a curta distância e autofecundação (cruzamento entre inflorescências no mesmo estipe e entre estipes da mesma touceira). A alta taxa de autofecundação registrada por Souza (2002) pode ser atribuída à ação da gravidade, uma vez que o açaizeiro apresenta caule múltiplo e possui dicogamia (protândria), sendo comum a ocorrência de inflorescências em diferentes estágios de floração no mesmo estipe e na mesma touceira, além das flores femininas exibirem estigmas expostos durante a antese.

A porcentagem de variação particionada contida entre as procedências com base nos marcadores co-dominantes foi um pouco menor $(5,97 \%)$ que a observada nos dominantes (Tabela 3). Como essas porcentagens apresentaram valores próximos (RAPD $=30,12 \%$ e SSR $=24,15 \%$ ), pode-se considerar que houve concordância do procedimento da AMOVA para a análise da distribuição da variabilidade das procedências de açaizeiro por essas duas classes de marcadores. Vale ressaltar que as porcentagens de variação particionada entre as procedências obtidas por esses dois marcadores poderiam ser menores se estivesse utilizado DNA dos próprios indivíduos nos locais de coleta e do recebido por intercâmbio ao invés dos bulks. Wadt \& Kageyama (2004) relatam dados de outras espécies vegetais, cujos níveis de diferenciação entre populações avaliadas por marcadores RAPD e isoenzimas foram similares.

De modo geral, o alto nível de diferenciação detectado entre procedências pode ter sido influenciado também pela ocorrência de altas taxas de autofecundação e de cruzamentos entre indivíduos aparentados dentro das mesmas. Esse evento parece comum na espécie em questão, uma vez que foi registrado em uma população natural sem a ação antrópica, $12,9 \%$ de cruzamentos entre indivíduos aparentados (Souza, 2002), ocasionado pelo longo e irregular período de floração e frutificação, produzindo vários estádios fenológicos de floração no mesmo estipe e na mesma touceira e pelo fluxo gênico a curta distância. Cardoso et al. (2000), também, sugeriram a ocorrência de autofecundação no palmiteiro (E. edulis Mart.), espécie monocaule, com emissão de inflorescências em diferentes estádios de floração e que apresenta protândria, mas não mencionaram o percentual. No caso das procedências aqui estudadas, cujos acessos são oriundos de populações naturais, esse fato pode ter sido incrementado pela deriva genética, ocasionada pela redução no tamanho, em conseqüência da exploração predatória para palmito, que sofreram as populações do açaizeiro. Já naquelas constituídas por acessos coletados em pomares e propriedades rurais, essa situação parece ainda mais grave, pois a deriva genética deve ter atuado com mais intensidade, em virtude do seu tamanho reduzido.

Como já relatado anteriormente, o conhecimento da distribuição da variabilidade genética entre e dentro dessas 
procedências é um quesito essencial para a adoção de estratégias eficientes na coleta e na conservação de germoplasma de espécies (Hamrick, 1982). Logo, com base nos resultados obtidos, podese sugerir que, nas próximas coletas dessa espécie, sejam obtidas amostras com maior número de frutos (pelo menos 100) de poucas matrizes em cada local, sendo conservado maior número de progênies (pelo menos 25) de cada matriz (acesso). Caso não seja possível, sugere-se seguir o número de amostras considerado para plantas alógamas por Vilela-Morales et al. (1997). Os resultados permitem supor, também, que as procedências constituídas por poucos acessos não sejam representativas da variabilidade genética existente nos locais de coleta, havendo necessidade de programar novas coletas, especialmente nas localidades do Maranhão.

TABELA 1 - Identificação das 17 procedências de açaizeiro avaliadas com base em marcadores RAPD e SSR e conservadas na Coleção de Germoplasma da Embrapa Amazônia Oriental, Belém-PA(2005).

\begin{tabular}{llc}
\hline Procedência & Local de coleta & $\mathrm{N}^{0}$ de acessos \\
\hline Benfica-PA & Pomar caseiro & 02 \\
Benevides-PA & Pomar caseiro & 04 \\
St $^{0}$ Ant ${ }^{0}$ do Tauá-PA & Propriedade rural & 05 \\
Chaves-PA & População natural & 15 \\
Muaná-PA & Propriedade rural & 11 \\
Breves-PA & População natural & 32 \\
Gurupá-PA & Pomar caseiro & 05 \\
Santarém-PA & Propriedade rural & 02 \\
Cametá-PA & População natural & 05 \\
Oiapoque-AP & População natural & 09 \\
Macapá-AP & Pomar caseiro & 05 \\
Maracaçumé-MA & Propriedade rural & 02 \\
Turiaçu-MA & População natural & 02 \\
Mirinzal-MA & População natural & 02 \\
Guimarães-MA & População natural & 02 \\
Alcântara-MA & População natural & 02 \\
Linhares-ES & Intercâmbio & 02 \\
\hline Total & & 107 \\
\hline
\end{tabular}

TABELA 3 - Análises de variância molecular obtidas para 17 procedências de açaizeiro, com base nos marcadores RAPD (263 bandas) e SSR (42 alelos).

\begin{tabular}{lcccc}
\hline Fonte de Variação & Variância & $\begin{array}{c}\text { Variação } \\
(\%)\end{array}$ & $P$ & $\Phi_{S T}$ \\
\hline RADP & 8,300 & 30,12 & 0,0001 & 0,301 \\
Entre procedências & 5,555 & 75,85 & & \\
$\begin{array}{c}\text { Dentro de procedências } \\
\text { SSR }\end{array}$ & & & & \\
Entre procedências & 1,769 & 24,15 & 0,0001 & 0,242 \\
Dentro de procedências & 19,206 & 69,88 & & \\
\hline
\end{tabular}

Maior $\phi_{S T}$ para 10.100 permutações: 0,305 (RAPD); 0,242 (SSR).
TABELA 2 - Identificação dos sete pares de primers SSR utilizados no estudo.

\begin{tabular}{|c|c|c|c|c|}
\hline $\begin{array}{c}\text { Primers } \\
\text { SSR }\end{array}$ & $\begin{array}{l}\mathrm{N}^{0} \text { de } \\
\text { repetições }\end{array}$ & Sequiência dos primers (5' a 3') & $\operatorname{Ta}\left({ }^{0} \mathrm{C}\right)^{1}$ & $\mathrm{Ta}\left({ }^{\circ} \mathrm{C}\right)^{2}$ \\
\hline$\overline{\mathrm{EE} 2}$ & $(\mathrm{AG})_{22}$ & $\begin{array}{l}\text { CCAAGGACGCAATCTCAA } \\
\text { AGCGAGGCAGAACACGTA }\end{array}$ & 62 & 56 \\
\hline EE3 & $(A G)_{11}(A G)_{16}$ & $\begin{array}{l}\text { TTCGCGCACACTGAGAG } \\
\text { GGTAGCGTTGATTGGTCC }\end{array}$ & 56 & 56 \\
\hline EE8 & $(A G)_{20}$ & $\begin{array}{l}\text { GTATTCCAATGTGCTCACAG } \\
\text { GTGCAGTAGGCTTCTAGTACC }\end{array}$ & 58 & 52 \\
\hline EE15 & $(\mathrm{AG})_{21}$ & $\begin{array}{l}\text { CCACACAGACACGCAGATAG } \\
\text { CCTCATGAAGCATCGACCT }\end{array}$ & 64 & 64 \\
\hline EE23 & $(\mathrm{A})_{14}(\mathrm{AG})_{23}$ & $\begin{array}{l}\text { GTTCTGCGATTCATACTCCTG } \\
\text { TACGAACCAAGATGGAGCAA }\end{array}$ & 58 & 56 \\
\hline EE43 & $(A G)_{16}$ & $\begin{array}{l}\text { GCGAAAGGCTAACAACGTTAT } \\
\text { AGCGAACCAACCAAGAAGAC }\end{array}$ & 56 & 50 \\
\hline EE54 & $(A G)_{25}$ & $\begin{array}{l}\text { CATGTATCTAAGGAACAAGG } \\
\text { СTGTGCTCTCTCATTCTCA }\end{array}$ & 56 & 50 \\
\hline
\end{tabular}

$\mathrm{Ta}^{1}$ : temperatura de anelamento sugerida por Gaiotto et al. (2001); $\mathrm{Ta}^{2}$ : temperatura de anelamento utilizada (Oliveira, 2005).

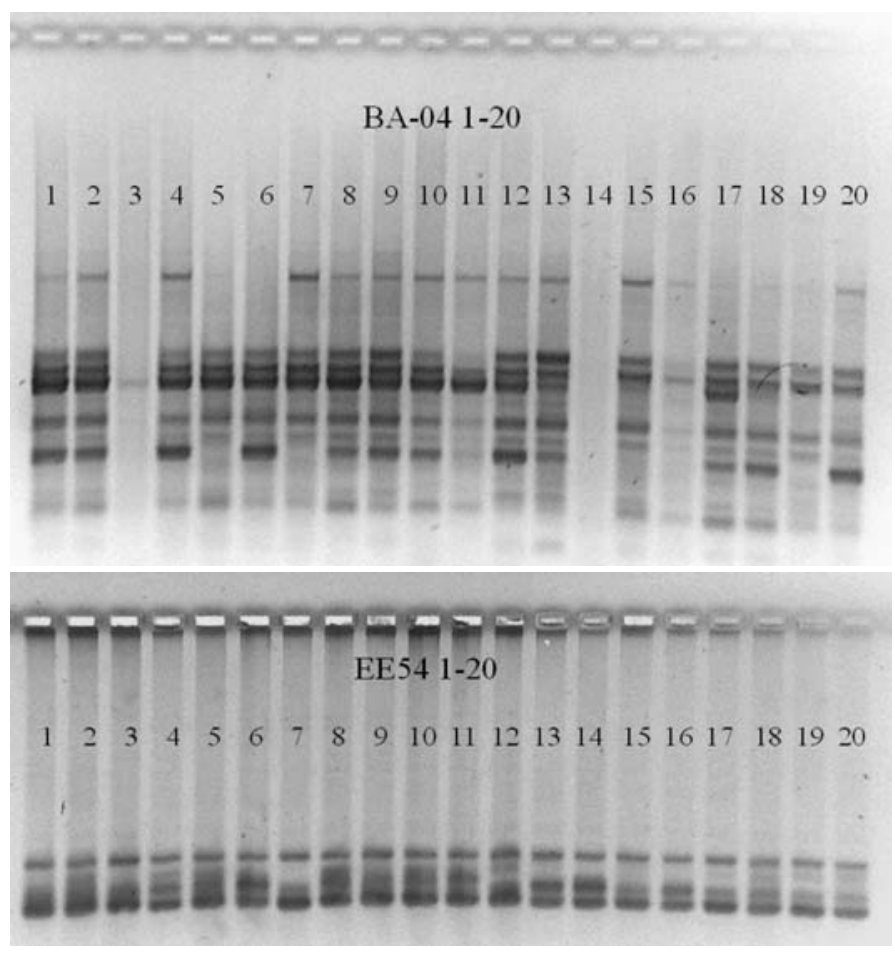

FIGURA 1 - Géis de agarose contendo exemplos de polimorfismos detectados pelos primers OPBA-04 (RAPD) e EE54 (SSR) nos acessos de 1 a 20 de açaizeiro utilizados neste estudo. 


\section{CONCLUSÕES}

1-Os marcadores RAPD e SSR são concordantes quanto à distribuição da variação genética entre e dentro de procedências dessa palmeira.

2-As procedências de açaizeiro conservadas na coleção de germoplasma da Embrapa Amazônia Oriental apresentam considerável nível de diferenciação genética entre si, com alta variabilidade genética dentro delas.

3-As procedências constituídas por poucos acessos não expressam a variabilidade genética existente nos locais de coleta. Logo, há a necessidade de se realizarem novas coletas para que estas procedências estejam bem representadas na coleção de germoplasma dessa palmeira.

4-Nas próximas coletas dessa espécie, sugere-se a obtenção de amostras com maior número de frutos retirados de poucas matrizes em cada local.

\section{REFERÊNCIAS}

ADIN, A.; WEBER, J.C.; SOTELO MONTES, C.; VIDAURRE, H.; VOSMAN, B.; SMULDERS, M.J.M. Genetic differentiation and trade among populations of peach palm (Bactris gasipaes Kunth) in the Peruvian Amazon - implications for genetic resource management. Theoretical and Applied Genetics, Berlin, v.108, n. 8, p. 1564-1573, May 2004.

ARAUJO, T.C.C. Estrutura da variabilidade genética e estrutura populacional de Caryocar brasiliense Camb. No Estado de Goiás utilizando marcadores RAPD. Goiânia, 2001. 87f. Dissertação (Mestrado em Ciências Biológicas) - Universidade Federal de Goiás. Goiânia, 2001

BAWA, K.S. Mating systems, genetic differentiation and speciation in tropical rain forest trees. Biotropica, St. Louis, v. 24, n. 2b, p.250-255, 1992.

CARDOSO, S.R.S.; ELOY, N.B.; PROVAN, J.; CARDOSO, M.A; FERREIRA, P.C.G. Genetic differentiation of Euterpe edulis Mart. Populations estimated by AFLP analysis. Molecular Ecology, Oxford, v.9, n. 11, p. 1753-1760, Nov. 2000.

CARVALHO, L.P. de.; LANZA, M.A.; FALLIERI, J.; SANTOS, J.W. dos. Análise da diversidade genética entre acessos de banco ativo de germoplasma de algodão. Pesquisa Agropecuária Brasileira, Brasília, v.38, n.10, p. 1149-1155, out. 2003.

CONTE, R. Estrutura genética de populações de Euterpe edulis Mart. submetidas à ação antrópica utilizando marcadores alozímicos e microssatélites. 2004. 124 f. Tese (Doutorado em Genética e Melhoramento de Plantas) - Escola Superior de Agricultura Luiz de Queiroz, Universidade de São Paulo, Piracicaba, 2004.
EXCOFFIER, L.E.; SMOUES, P.E.; QUATTRO, J.M. Analysis of molecular variance inferred from metric distances among DNA haplotypes: application to human mitocondrial DNA restriction data. Genetics, Austin, v. 131, p. 479-491, 1992.

FONTAINE, C.; LOVETT, P.N.; SANOU, H.; MALEY, J. BOUVET, J.M. Genetic diversity of the shea tree (Vitellaria paradoxa C.F. Gaertn), detected by RAPD and chloroplast microsatellite marckers. Heredity, London, v.93, n. 6, p. 639-647, Dec. 2004.

HAMRICK, J.L. Plant population genetics and evolution. American Journal of Botany, Columbus, v. 69, n. 10, p. 1685$1693,1982$.

HAYATI, A.; WICKNESWARI, R.; MAIZURA, I.; RAJANAIDU, N. Genetic diversity of oil palm (Elaeis guineensis Jacq.) germoplasm collections from Africa: implications for improvement and conservation of genetic resoucers. Theoretical and Applied Genetics, Berlin, v.108, n.7, p. 1274-1284, 2004.

MOHAMMADI, S.A.; PRASANNA, B.M. Analysis of genetic diversity in crop plant - Salient statistical tools and considerations. Crop Science, Madison, v.43, n. 4, p. 1235-1248, July/Aug. 2003.

MORETZSOHN, M.C.; FERREIRA, M.A.; AMARAL, Z.P.S.; COELHO, P.J.A.; GRATTAPAGLIA, D.; FERREIRA, M.E. Genetic diversity of Brazilian oil palm (Elaeis oleifera H.B.K.) germplasm collected in the Amazon Forest. Euphytica, Wageningen, v.124, n. 1, p. 35-45, 2002.

MOURA, E. F.; PINTO, J. E. B. P.; SANTOS, J. B. dos; LAMEIRA, O. A. Genetic diversity in a jaborandi (Pilocarpus microphyllus Stapf.) germplasm bank assessed by RAPD markers.. Revista Brasileira de Plantas Medicinais, Botucatu, v. 7, n. 3, p. 1-8, 2005.

NIENHUIS, J.; TIVANG, J.; SCKROCH, P.; SANTOS, J. B dos. Genetic relations among cultivars and lines of lima bean (Phaseolus lunatus L.) as measured by RAPD marker. Journal of American Society for Horticultural Science, Alexandria, v. 120, n. 2, p. 300-306, Mar. 1995.

OLIVEIRA, M. do S. P. de. Caracterização molecular e morfoagronômica de germoplasma de açaizeiro. 2005. $171 \mathrm{f}$. Tese (Doutorado em Genética e Melhoramento de Plantas) Universidade Federal de Lavras, Lavras, 2005.

OLIVEIRA, M. do S. P. de.; FARIAS NETO, J.T de; PENA, R. da S. Açaí: técnicas de cultivo e processamento. Fortaleza: Instituto Frutal, 2007. 104p.

PERERA, L.; RUSSELL, J.R.; PROVAN, J.; POWELL, W. Levels and distribution of genetic diversity of coconut (Cocos nucifera L., var. Typica form typica) from Sri Lanka assessed by 
microsatellite markers. Euphytica, Wageningen, v. 122, n. 2, p. 381-389, 2001

RODRIGUES, D.; ASTOLFI FILHO, S.; CLEMENT, C.R. Molecular marker-mediated validation of morphologically defined landraces of pejibaye (Bactris gasipaes) and their phylogenetic relationships. Genetic Resources and Crop Evolution, Dordrecht, v.51,p. 871-882, 2004.

ROTMAM, W.; BOYLE, T.J. Effects of logging and others forms of harvesting in humid tropical forest. In: YOUNG, A.; BOSHIER, D.; BOYLE, T. (Ed.). Forest conservation genetics, principles and practice. Australia: CSIRO, 2000. p. 115-122.

SCHNEIDER, S.; ROESSLI, D.; EXCOFFIER, L. Arlequin: a software for population genetics data analysis, version 2.000. Switzerland: University of Geneva, Genetics and Biometry Laboratory, 2000.

SENIOR, M.L.; MURPHY, J.P.; GOODMAN, M.M.; STUBER, C.W. Utility of SSRs for determining genetic similarities and relationships in maize using an agarose gel system. Crop Science, Madison, v.38, p.1088-1098, 1998.
SOUZA, P.C.A de. Aspectos ecológicos e genéticos de uma população natural de Euterpe oleracea Mart. no estuário amazônico. 2002. 60 f. Dissertação (Mestrado em Recursos Florestais) - Escola Superior de Agricultura "Luiz de Queiroz", Univesidade de São Paulo, Piracicaba, 2002.

VILELA-MORALES, E.A.; VALOIS, A. C. C.; NASS, L.L. Recursos genéticos vegetales. Brasília: Embrapa-SPI/EmbrapaCenargen, $1997.78 \mathrm{p}$.

WADT, L.H de O.; KAGEYAMA, P.Y. Estrutura genética e sistema de acasalamento de Piper hispidinervum. Pesquisa Agropecuária Brasileira, Brasília, v.39, n. 2, p. 151-157, fev, 2004.

ZUCCHI, M. I.; BRONDANI, R. V.; PINHEIRO, J. B.; COELHO, A. S. G.; CHAVES, L. J.; VENCOVSKY, R. Genetic structure and gene flow in Eugenia dysenterica DC in the brazilian cerrado utilizing SSR markers. Genetics and Molecular Biology, Ribeirão preto, v. 26, n. 4, p. 449-458, 2003.

ZUCCHI, M. I.; PINHEIRO, J. B.; COELHO, A. S. G.; MORAIS, L. K. de; COUTO, M. A.; CHAVES, L. J.; VENCOVSKY, R. Genetic structure and gene flow in Eugenia dysenterica DC in brazilian cerrado utilizing RAPD markers. Pesquisa Agropecuária Brasileira, Brasília, v. 40, n. 10, p. 975-980, 2005. 